\title{
Association of working hours, job position, and BMI with work-related musculoskeletal disorders among the physiotherapists of Gujarat-an observational study
}

Vivek H. Ramanandi ${ }^{1,2^{*}}$ (D) and Anjan R. Desai ${ }^{2,3}$

\begin{abstract}
Background: Physiotherapists are prone to develop work-related musculoskeletal disorders (WMSDs). Region wise distribution and frequency of work disturbance have been studied in physiotherapists but exploration of the probable association of working hours, job position, and body mass index (BMI) with WMSDs is not adequately done in the Gujarat, India. Hence, the present study was undertaken to investigate these aspects among the physiotherapists of Gujarat.
\end{abstract}

Results: An online cross-sectional survey including 322 physiotherapists was conducted and the data was collected after gaining informed electronic consent. Present study showed no significant co-relation between job position (0.602), weekly working hours (0.930), and BMI (0.589) with WMSDs prevalence. The 1-year work disturbance and 1week musculoskeletal difficulties were found to be due to low back-related complaints (35.09\%, 33.85\%).

Conclusion: It is inferred that high prevalence of WMSDs in physiotherapists may be due to one of various factors including job position, working hours, and BMI but they are not significantly correlated with WMSDs.

Keywords: Musculoskeletal disorders, Occupational Health, Occupational injury, Physical Therapists, Prevalence, Risk factors

\section{Background}

Work-related musculoskeletal disorders (WMSDs) have become very common worldwide recently [1]. They can be described as inflammatory and degenerative diseases and disorders that result in pain and functional impairment [2]. According to World Health Organization (WHO), any health problem of the locomotor apparatus including all forms of reversible, light, transitory disorder or irreversible, disabling injuries of the nerves, tendons, muscles, bones, joints, ligaments, spinal disc, cartilage, and blood vessels can be defined as WMSDs [3, 4]. Repetitive demanding working conditions associated with

\footnotetext{
* Correspondence: vivekramanandi@gmail.com

${ }^{1}$ Gujarat University, Ahmedabad, India

${ }^{2}$ SPB Physiotherapy College, Surat, India

Full list of author information is available at the end of the article
}

rapid industrialization and increasing needs of healthcare facilities represent one of the biggest problems causing WMSDs in variety of professions [5]. According to previous studies, physiotherapists typically report a higher incidence of WMSDs and are at high risk of developing long-term disabilities associated with them [6-8].

Physiotherapists in routine training and practice are prone to variety of physical and psychological stressors [9]. Multifactorial mechanisms are reported to be responsible for pain and disorders related to work. They may include but are not limited to numerous risk factors such as repetitive excessive strain on the spine; prolonged awkward static postures (stooping, slouching, ducking); poor positioning; repetitive movements of neck and shoulder flexion/abduction; prolonged application of manual strength; inadequate work breaks; coping 
with patient's anxieties-mental stress; genetic predisposition; physical conditioning; age; time pressure; high demand and poor social support etc. [5, 8-10]. One of the previous studies has reported that the postures attained during work, which requires more than $50 \%$ of the body's muscles to contract to hold the body static against the force of gravity, is one of the most significant physical factor [11]. It is also reported that with increase in the age and years of clinical work, the static forces because of such postures can affect much more than dynamic forces and can result in musculoskeletal pain [12].

One of the previous studies conducted by Cromie et al. (2000) reported that the lifetime prevalence of WMSDs was $91 \%$. They also found that 1 in 6 physical therapists moved within by changing specialty practice or setup or left the profession due to WMSDs [13]. In a nationwide study of Indian physiotherapists, Muruganatham et al. (2015) suggested highest prevalence of WMSDs (42.01\%) between 22 and 25 years of age where majority of physiotherapists (35.48\%) first experienced their WMSDs within 5 years of graduation $[14,15]$.

Several studies have assessed the prevalence of WMSDs and the effects of specific anatomic site, gender, posture etc. on physiotherapists in India [14-16]. However, the studies related to the exposure assessments and studies exploring the association of WMSDs with various factors were found to be inadequate for determining the effect of those factors. Therefore, this study aimed to investigate the relationship of WMSDs with working hours, job position, and body mass index (BMI) among the qualified physiotherapists having minimum graduate degree from Gujarat State in India. Exploration of work pattern disturbance was done to find out the reporting of disturbed work pattern within 12 months and 7 days due to WMSDs.

\section{Methods}

The clinicians and teachers from physiotherapy profession were invited from all over Gujarat State to fill up a Google form circulated through e-mails, social media and personal messages for this internet based online survey which lasted from 8th to 22th November 2020. Three hundred twenty-two responses from total of 351 were considered for analysis due to incomplete or unclear data of the remaining responses.

Subjects who were qualified physiotherapists having at least undergraduate professional degree and worked for at least $6 \mathrm{~h}$ per week clinically were included after agreeing to participate by checking in the electronic participation consent. Each subject was required to fill up an assessment form consisting of questions regarding their basic demographic details; professional details such as job/position, experience, weekly working hours, and health information using standardized Nordic Musculoskeletal Questionnaire (NMQ) and submit it online.

The nature and severity of self-reported musculoskeletal complaints with respect to 9 body areas were assessed using standardized NMQ. It is a symptom questionnaire, designed for all musculoskeletal symptoms and captures occurrences of such symptoms over the past 7 days (weekly prevalence) and over the past 12 months (annual prevalence). The tool was developed to be used as a questionnaire or as a structured interview $[17,18]$. Based on the previous studies, the kappa values for 27 variables ranged between 0.57 and 1.00 in the reliability assessment. The kappa value for criterion validity for the agreement between participants' clinical records and questionnaires was found to be 0.76 [19].

Data were collected and analyzed for association between WMSDs and weekly working hours, Job position and BMI. Frequencies of disturbance of work pattern within previous 12 months and 7 days due to WMSDs were analyzed. Basic descriptive analysis and graph generation was done using Microsoft Excel for Windows, whereas chi-square test of association for finding association was done using SPSS 20 for Windows.

\section{Results}

Descriptive statistics showed the gender and age group distribution of the sample having more female respondents (79.19\%) and more subjects from younger age groups, i.e., $25-30$ years $(58.07 \%)$ and $31-35$ years (27.02\%). It showed that $141(43.79 \%)$ respondents were full-time working clinical physiotherapists and that approximately half of physiotherapists $(n=171,54.04 \%)$ worked 5-6 h daily. Distribution of physiotherapists according to BMI categories reflected that most of the physiotherapists $(n=157,48.76 \%)$ were from normal or lean category having BMI between 18.5 and $22.9 \mathrm{~kg} / \mathrm{m}^{2}$. The mean BMI was calculated to be $24.08+4.38 \mathrm{~kg} / \mathrm{m}^{2}$ among the total study population (Table 1 ).

The distribution of physiotherapists having WMSDs based upon their job position, weekly working hours, and BMI categories was calculated from the results. It showed that the highest prevalence of WMSDs (i.e., $70.92 \%$ ) was present in the physiotherapists working as a full-time clinician whereas lowest number of WMSDs was present in the physiotherapists working as part-time clinician (i.e., 63.27\%). The highest number of WMSDs (i.e., 81.25\%) was present in the physiotherapists working for weekly 37-43 h whereas lowest number of WMSDs was present in the physiotherapists working less than 18 $\mathrm{h}$ per week. More than $60 \%$ physiotherapists in all the BMI categories reported about WMSDs with the highest number of WMSDs (i.e., 73.44\%) present in the physiotherapists from overweight category (Table 2). 
Table 1 Descriptive statistics $(n=322)$

\begin{tabular}{|c|c|c|c|}
\hline Characteristic & & Frequency $(n)$ & Percentage (\%) \\
\hline \multirow[t]{2}{*}{ Gender } & Male & 67 & 20.81 \\
\hline & Female & 255 & 79.19 \\
\hline \multirow[t]{5}{*}{ Age (years) } & $25-30$ & 187 & 58.07 \\
\hline & $31-35$ & 87 & 27.02 \\
\hline & $36-40$ & 26 & 8.07 \\
\hline & $41-45$ & 18 & 5.59 \\
\hline & $>45$ & 4 & 1.24 \\
\hline \multirow[t]{4}{*}{ Job position } & Post-graduate student & 5.91 & 19 \\
\hline & Full-time clinician & 43.79 & 141 \\
\hline & Academician & 35.09 & 113 \\
\hline & Part-time clinician & 15.22 & 49 \\
\hline \multirow[t]{7}{*}{ Weekly working hours } & $7-12 \mathrm{~h}$ & 0.62 & 2 \\
\hline & $13-18 \mathrm{~h}$ & 5.28 & 17 \\
\hline & $19-24 \mathrm{~h}$ & 13.35 & 43 \\
\hline & $25-30 \mathrm{~h}$ & 25.78 & 83 \\
\hline & $31-36 h$ & 28.26 & 91 \\
\hline & $37-42 h$ & 14.91 & 48 \\
\hline & More than $42 \mathrm{~h}$ & 11.80 & 38 \\
\hline \multirow{4}{*}{$\begin{array}{l}\text { BMI categories } \\
\left(\mathrm{kg} / \mathrm{m}^{2}\right)\end{array}$} & < 18.5 (underweight) & 16.15 & 52 \\
\hline & 18.5-22.9 (normal or lean) & 48.76 & 157 \\
\hline & 23.0-24.9 (overweight) & 19.88 & 64 \\
\hline & $\geq 25$ (obese) & 15.22 & 49 \\
\hline
\end{tabular}

Table 2 Specific characteristic wise prevalence of MSDs $(n=322)$

\begin{tabular}{|c|c|c|c|c|}
\hline Characteristic & & Frequency $(n)$ & $\operatorname{MSD}(n)$ & MSD (\%) \\
\hline \multirow[t]{4}{*}{ Job position } & Post-graduate student & 19 & 13 & 68.42 \\
\hline & Full-time clinician & 141 & 100 & 70.92 \\
\hline & Academician & 113 & 72 & 63.72 \\
\hline & Part-time clinician & 49 & 31 & 63.27 \\
\hline \multirow[t]{7}{*}{ Weekly working hours } & $7-12 \mathrm{~h}$ & 2 & 0 & 0 \\
\hline & $13-18 \mathrm{~h}$ & 17 & 5 & 29.41 \\
\hline & $19-24 \mathrm{~h}$ & 43 & 26 & 60.47 \\
\hline & $25-30 h$ & 83 & 52 & 62.65 \\
\hline & $31-36 h$ & 91 & 67 & 73.63 \\
\hline & $37-42$ h & 48 & 39 & 81.25 \\
\hline & More than $42 \mathrm{~h}$ & 38 & 27 & 71.05 \\
\hline \multirow[t]{4}{*}{ BMI categories $\left(\mathrm{kg} / \mathrm{m}^{2}\right)$} & < 18.5 (underweight) & 52 & 36 & 69.23 \\
\hline & 18.5-22.9 (normal or lean) & 157 & 102 & 64.97 \\
\hline & 23.0-24.9 (overweight) & 64 & 47 & 73.44 \\
\hline & $\geq 25$ (obese) & 49 & 31 & 63.27 \\
\hline Total & & 322 & 216 & 67.8 \\
\hline
\end{tabular}


Table 3 shows the values of chi-square test of association for job position, BMI category, and weekly working hours with the prevalence of WMSDs in physiotherapists. The results show that the $p$ values are statistically not significant at $\alpha=0.05$ levels indicating that no variable is significantly associated with the prevalence of WMSDs.

Fig. 1 indicates frequencies of disturbance of work pattern within previous 12 months and musculoskeletal troubles within previous 7 days due to WMSDs in physiotherapists distributed on the basis of anatomical region being affected.

\section{Discussion}

The results of present study reveal that weekly working hours, BMI, and job position of a physiotherapist do not have any significant relation with the disorders of musculoskeletal system.

Globally, numbers of studies have reported that incidences of WMSDs are on rise, despite the development of new and innovative equipment to make clinical practice of physiotherapists easier [10, 20-22]. It is already suggested that cumulative effect of chronic fatigue, discomfort, and pain along with the poor work habits, e.g., poor posture can lead to development of musculoskeletal symptoms [6, 9, 22]. Reducing direct patient-contact hours has been reported to be the most used strategy to overcome the effects of WMSDs by physiotherapists $[3,13,16]$. In addition, as physiotherapists work on an average for 45-60 min with a patient during single session they become more prone to development of WMSDs with increase in working hours [15]. The main finding of present study suggested that the weekly working hours do not correlate with the prevalence of work-related MSDs. Contradicting findings were found in a study from India, where, WMSDs were found to be more prevalent in the younger physiotherapists which was thought to be because of the reason that younger physiotherapists work usually for more hours and work more vigorously [15]. However, Bork et al. (1996) found that the physiotherapists $>50$ years of age the higher patient-contact hours per week and still had lower prevalence of WMSDs probably due to survivor bias and experience based learning [3]. Holder et al. (1999) reported highest injury prevalence in PTs and PTAs who worked between 41 and $50 \mathrm{~h}$ per week which was similar to the findings of this study [6].
The work setting of a physiotherapist is reported to affect the prevalence and severity of WMSDs [3, 16, 23]. The prevalence of injury at a specific anatomical location was reported to vary with the practice setting where physiotherapists work [6]. Present study reported 72.93\% prevalence of WMSDs in full-time clinicians whereas academicians, part-time clinicians, and post-graduate students reported identical prevalence. Bork et al. (1996) said that physical therapists who worked in hospitalbased settings had a greater prevalence of work-related musculoskeletal symptoms in the low back than did non-hospital-based therapists which was contradictory to this study [3]. Buddhdev and Kotecha (2012) also reported higher prevalence in clinical practitioners (approximately 55\%) as compared to the academicians (10\%). All these previous studies are in line with the findings of present study suggesting impact of job position or work setting with WMSDs in physiotherapists. Further exploration of region wise comparison on the basis of work setting can provide understanding about the effect of job position on the anatomical region of the body.

Furthermore, present study revealed higher prevalence of WMSDs in higher BMI category physiotherapists who were overweight. An Indian study by Maheshwari et al. (2015) reported similar findings with majority of physiotherapists in normal or lean category similar to present study [15].

Lower back-related issues were found to be most responsible when region wise impact of WMSDs on 1 year work disturbance pattern $(35.09 \%)$ and 1 week musculoskeletal issues (33.85\%) were analyzed followed by upper back and neck regions. The pattern is similar to the many previous studies which reported lower back, neck, and upper back to be the reason for change of work setting, specialty, or profession for physiotherapists $[2,6,13,24]$.

This study highlights the need to train and practice preventive measures for avoidance of WMSDs during professional practice for physiotherapists. The role of efficient and health ergonomics, healthy work environment, injury prevention, counseling, etc., must be focused to decrease the prevalence of WMSDs and increase the productivity of physiotherapists [25].

The study has its limitations like any other study. The responses of physiotherapists from higher age group were few as the data was collected using online survey

Table 3 Chi-square values for association between the variables ( $a=0.05$ )

\begin{tabular}{lllll}
\hline Variables & Chi-square value & Degree of freedom & $\begin{array}{l}\boldsymbol{P} \text { value } \\
\text { (2-sided) }\end{array}$ & Statistical significance \\
\hline Job position & 1.86 & 3 & 0.602 & Not significant \\
BMl category & 1.62 & 3 & 0.589 & \\
Weekly working hours & 1.88 & 6 & 0.930 & \\
\hline
\end{tabular}




\section{Region Wise Work Disturbance and Musculoskeletal Troubles}

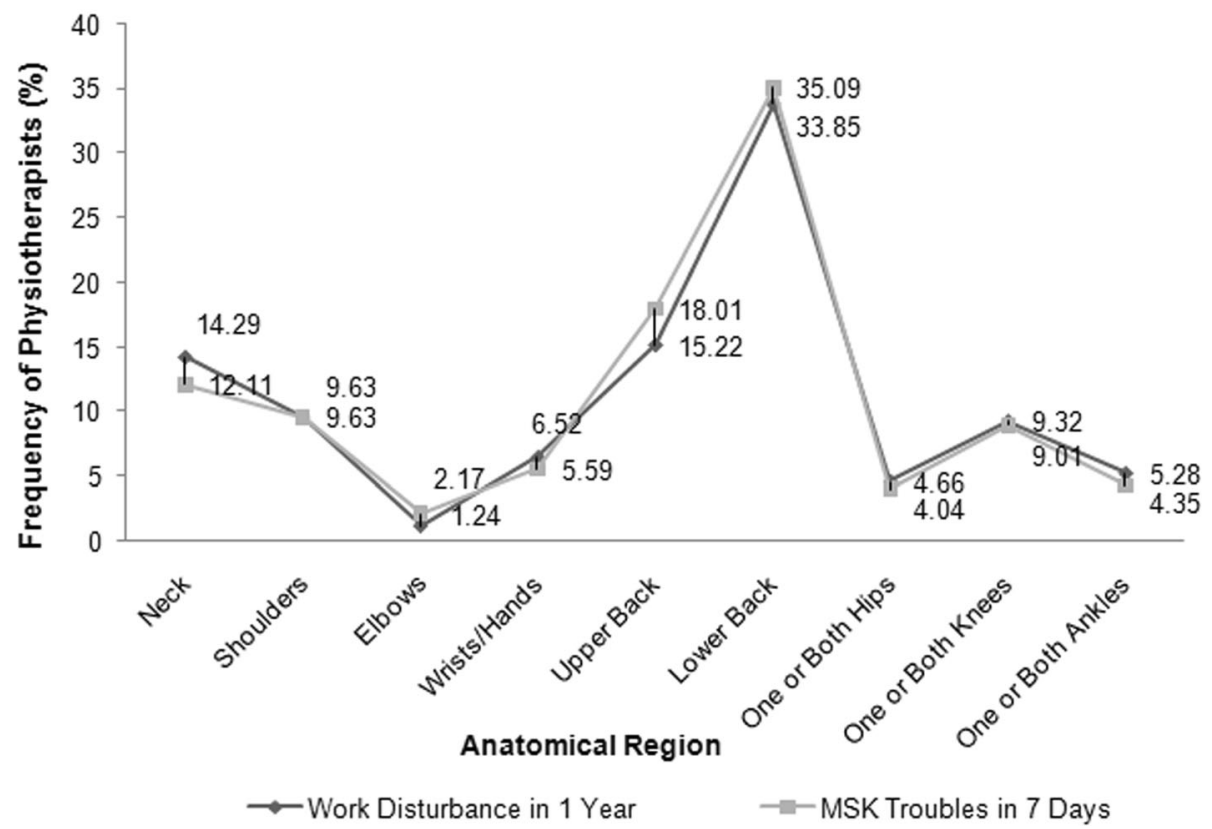

Fig. 1 Region wise work disturbance and musculoskeletal troubles ( $n=322$ )

technique, and they may be less familiar with use of such methods. This can be overcome by conducting inperson survey for such physiotherapists using printed survey form. Further, participant memory could have affected their responses as the survey included selfreported measure, and this might have in turn affected results.

\section{Conclusion}

Present study shows that there is a no significant relation of job position, weekly working hours, or BMI with prevalence rate of WMSDs. The WMSDs in physiotherapists are mostly affecting lower back and neck and are one of the major reasons for work disturbances and difficulties for physiotherapists.

\section{Abbreviations}

WMSDs: Work-related musculoskeletal disorders; MSDs: Musculoskeletal disorders; BMI: Body mass index; WHO: World Health Organization; NMQ: Nordic Musculoskeletal Questionnaire

\section{Acknowledgements}

The authors would like to thank Principal and all the staff members of SPB Physiotherapy College, Surat; and all the physiotherapists from all over Gujarat who participated with zeal to provide necessary data.

\section{Authors' contributions}

VR and AD conceptualized and designed the study methodologically as well as collected, analyzed, and interpreted the data, and are equal contributors in writing and revising the manuscript. All authors have read and approved the manuscript.

\section{Funding}

No financial support was received.

\section{Availability of data and materials}

Data will be shared on specific request to the author depending upon the nature and purpose of the requirement.

Ethics approval and consent to participate

Ethics approval was received from IEC (Ref. No. EC/SPB/032, dt. 07/11/2020) of SPB Physiotherapy College, Surat.

Electronic participation consent was taken for each subject after providing written information about the study at the start of survey.

\section{Consent for publication}

Not applicable.

\section{Competing interests}

No competing interests.

\section{Author details}

${ }^{1}$ Gujarat University, Ahmedabad, India. ${ }^{2}$ SPB Physiotherapy College, Surat, India. ${ }^{3}$ Parul University, Waghodia, India.

Received: 12 December 2020 Accepted: 26 January 2021

Published online: 15 February 2021

\section{References}

1. Alexopoulos EC, Stathi I-C, Charizani F. Prevalence of musculoskeletal disorders in dentists. BMC Musculoskelet Disord. 2004:5(1):1-6 1.

2. Scholey M, Hair M. Back pain in physiotherapists involved in back care education. Ergonomics. 1989;32(2):179-90. https://doi.org/10.1080/ 00140138908966078.

3. Bork BE, Cook TM, Rosecrance JC, Engelhardt KA, Thomason M-EJ, Wauford IJ, et al. Work-related musculoskeletal disorders among physical therapists. Phys Ther. 1996;76(8):827-35

4. Shaik AR, Rao SB, Husain A, D'sa J. Work-related musculoskeletal disorders among dental surgeons: a pilot study. Contemp Clin Dent. 2011;2(4):308-12. 
5. Batham C, Yasobant S. A risk assessment study on work-related musculoskeletal disorders among dentists in Bhopal, India. Indian J Dent Res. 2016;27(3):236-41

6. Holder NL, Clark HA, DiBlasio JM, Hughes CL, Scherpf JW, Harding L, et al. Cause, prevalence, and response to occupational musculoskeletal injuries reported by physical therapists and physical therapist assistants. Phys Ther 1999;79(7):642-52

7. Iqbal Z, Alghadir A. Prevalence of work-related musculoskeletal disorders among physical therapists. Med Pr. 2015;66(4):459-69.

8. Al-Eisa E, Buragadda S, Shaheen A, Ibrahim A, Melam GR. Work related musculoskeletal disorders: causes, prevalence and response among Egyptian and Saudi physical therapists. Middle-East J Sci Res. 2012;12(4): 523-9.

9. Pejčić N, Petrović V, Marković D, Miličić B, Dimitrijević Il, Perunović N, et al. Assessment of risk factors and preventive measures and their relations to work-related musculoskeletal pain among dentists. Work. 2017;57(4):573-93.

10. Campo M, Weiser S, Koenig KL, Nordin M. Work-related musculoskeletal disorders in physical therapists: a prospective cohort study with 1-year follow-up. Phys Ther. 2008;88(5):608-19.

11. Paldhikar S, Bhatkar S, Ghodey S. Incidence and study of occupational factors associated with low back pain in dentists in Pune region India. IOSR J Dent Med Sci (JDMS). 2012;3:08-12.

12. Joshi Medhavi H, Desai Devangi S, Singh Lalli M, Joshi VA. Correlation between work experience and musculoskeletal disorders among the dentists of Vadodara, Gujarat, India. Int J Res Rev. 2019;6(12):27-32.

13. Cromie JE, Robertson VJ, Best MO. Work-related musculoskeletal disorders in physical therapists: prevalence, severity, risks, and responses. Phys Ther. 2000;80(4):336-51.

14. Muruganantham B, Nayak B, Dave D, Kotia P. Work-related musculoskeletal disorders among Indian Physiotherapists. Physiotherapy. 2015;101:e1059-e60

15. Maheshwari P, Soni R, Parkash N. Work related musculoskeletal disorders: a survey of physiotherapists in tricity. Int J Physiother. 2015;2(6):1091-6.

16. Buddhadev NP. Work-related musculoskeletal disorders: a survey of physiotherapists in Saurashtra region. Age (years). Natl J Med Res. 2012; 21(25):179-81.

17. Kuorinka I, Jonsson B, Kilbom A, Vinterberg H, Biering-Sørensen F, Andersson G, et al. Standardised Nordic questionnaires for the analysis of musculoskeletal symptoms. Appl Ergon. 1987;18(3):233-7.

18. Crawford JO. The Nordic musculoskeletal questionnaire. Occup Med. 2007: 57(4):300-1.

19. Legault ÉP, Cantin V, Descarreaux M. Assessment of musculoskeletal symptoms and their impacts in the adolescent population: adaptation and validation of a questionnaire. BMC Pediatr. 2014;14(1):1-8.

20. Glover W, McGregor A, Sullivan C, Hague J. Work-related musculoskeletal disorders affecting members of the Chartered Society of Physiotherapy. Physiotherapy. 2005;91(3):138-47.

21. Sharan D, Ajeesh P. Injury prevention in physiotherapists-a scientific review. Work. 2012:41(Supplement 1):1855-9.

22. Nkhata LA, Zyaambo C, Nzala S, Siziya S. Work-related musculoskeletal disorders: Prevalence, contributing factors and coping strategies among physiotherapy personnel in Lusaka, Kitwe and Ndola districts, Zambia. Med J Zambia. 2010;37(4):262-7.

23. Malarvizhi D, Kumar MK, Sivakumar VPR. Prevalence of work-related musculoskeletal disorders among clinical and teaching physiotherapists - an observational study. Int J Physiother. 2017;4(2):86-92.

24. Prerana S, Saravanan M, Krunal L, Krishna R, Ruchi V. Prevalence, risk factors and coping strategies to work related musculoskeletal disorders reported by physiotherapists in Surat district, India. Physiotherapy. 2015;101:e1338.

25. Soukup MG, LÖnn J, GlomsrÖd B, BÖ K, Larsen S. Exercises and education as secondary prevention for recurrent low back pain. Physiother Res Int. 2001; 6(1):27-39.

\section{Publisher's Note}

Springer Nature remains neutral with regard to jurisdictional claims in published maps and institutional affiliations.

\section{Submit your manuscript to a SpringerOpen ${ }^{\circ}$ journal and benefit from:}

- Convenient online submission

- Rigorous peer review

- Open access: articles freely available online

- High visibility within the field

- Retaining the copyright to your article

Submit your next manuscript at $\boldsymbol{\nabla}$ springeropen.com 